\title{
Performance of human observers and an automatic 3-dimensional computer-vision-based locomotion scoring method to detect lameness and hoof lesions in dairy cows
}

\author{
Andrés Schlageter-Tello, ${ }^{\star 1}$ Tom Van Hertem, $†$ Eddie A. M. Bokkers, $\ddagger$ Stefano Viazzi, $†$ Claudia Bahr,§ \\ and Kees Lokhorst*\# \\ *Wageningen UR Livestock Research, PO Box 338, 6700 AH, Wageningen, the Netherlands \\ †Division Measure, Model and Manage Bioresponses, KU Leuven, PO Box 2456, 3001 Heverlee, Belgium \\ $\ddagger$ Animal Production Systems Group, Wageningen University, PO Box 338, $6700 \mathrm{AH}$, Wageningen, the Netherlands \\ $\S$ Agrifirm Innovation Center B.V., Landgoedlaan 20, 7302 HA, Apeldoorn, the Netherlands \\ \#Van Hall Larenstein University of Applied Science, PO Box 1528, 8901 BV, Leeuwarden, the Netherlands
}

\begin{abstract}
The objective of this study was to determine if a 3-dimensional computer vision automatic locomotion scoring (3D-ALS) method was able to outperform human observers for classifying cows as lame or nonlame and for detecting cows affected and nonaffected by specific type(s) of hoof lesion. Data collection was carried out in 2 experimental sessions ( 5 mo apart). In every session all cows were assessed for (1) locomotion by 2 observers (Obs1 and Obs2) and by a 3D-ALS; and (2) identification of different types of hoof lesions during hoof trimming (i.e., skin and horn lesions and combinations of skin/horn lesions and skin/hyperplasia). Performances of observers and 3D-ALS for classifying cows as lame or nonlame and for detecting cows affected or nonaffected by types of lesion were estimated using the percentage of agreement (PA), kappa coefficient $(\kappa)$, sensitivity (SEN), and specificity (SPE). Observers and 3D-ALS showed similar $\mathrm{SEN}_{\text {lame }}$ values for classifying lame cows as lame $\left(\mathrm{SEN}_{\text {lame }}\right.$ comparison Obs1-Obs2 = 74.2\%; comparison observers-3D-ALS $=73.9-71.8 \%$ ). Specificity values for classifying nonlame cows as nonlame were lower for 3D-ALS when compared with observers $\left(\mathrm{SPE}_{\text {nonlame }}\right.$ comparison Obs1-Obs2 $=88.5 \%$; comparison observers-3D-ALS $=65.3-67.8 \%$ ). Accordingly, overall performance of 3D-ALS for classifying cows as lame and nonlame was lower than observers (Obs1Obs2 comparison $\mathrm{PA}_{\text {lame } / \text { nonlame }}=84.2 \%$ and $\kappa_{\text {lame/nonlame }}$ $=0.63 ;$ observers-3D-ALS comparisons $\mathrm{PA}_{\text {lame/nonlame }}$ $=67.7-69.2 \%$ and $\left.\kappa_{\text {lame } / \text { nonlame }}=0.33-0.36\right)$. Similarly, observers and 3D-ALS had comparable and moderate $\mathrm{SEN}_{\text {lesion }}$ values for detecting horn $\left(\mathrm{SEN}_{\text {lesion }} \mathrm{Obs1}=\right.$
\end{abstract}

Received August 30, 2017.

Accepted February 24, 2018

${ }^{1}$ Corresponding author: andres_schlageter@yahoo.com
$68.6 \%$; Obs2 $=71.4 \% ; 3 \mathrm{D}-\mathrm{ALS}=75.0 \%)$ and combinations of skin/horn lesions $\left(\mathrm{SEN}_{\text {lesion }} \mathrm{Obs1}=51.1 \%\right.$; Obs2 $=64.5 \%$; 3D-ALS $=53.3 \%$ ). The $\mathrm{SPE}_{\text {nonlesion }}$ values for detecting cows without lesions when classified as nonlame were lower for 3D-ALS than for observers $\left(\mathrm{SPE}_{\text {nonlesion }} \mathrm{Obs} 1=83.9 \% ;\right.$ Obs2 $=80.2 \% ; 3 \mathrm{D}-\mathrm{ALS}=$ $60.2 \%)$. This was translated into a poor overall performance of 3D-ALS for detecting cows affected and nonaffected by horn lesions $\left(\mathrm{PA}_{\text {lesion/nonlesion }} \mathrm{Obs} 1=80.6 \%\right.$; Obs2 $=78.3 \% ; 3 \mathrm{D}-\mathrm{ALS}=63.5 \%$ and $\kappa_{\text {lesion} / \text { nonlesion }} \mathrm{Obs} 1$ $=0.48 ;$ Obs2 $=0.44 ; 3 \mathrm{D}-\mathrm{ALS}=0.25)$ and skin/horn lesions $\left(\mathrm{PA}_{\text {lesion} / \text { nonlesion }}\right.$ Obs1 $=75.1 \%$; Obs2 $=75.9 \%$; $3 \mathrm{D}-\mathrm{ALS}=58.6 \%$ and $\kappa_{\text {lesion } / \text { nonlesion }}$ Obs1 $=0.35 ;$ Obs2 $=0.42 ; 3 \mathrm{D}-\mathrm{ALS}=0.10)$, when compared with observers. Performance of observers and 3D-ALS for detecting skin lesions was poor $\left(\mathrm{SEN}_{\text {lesion }}\right.$ for Obs1, Obs2, and 3DALS <40\%). Comparable $\mathrm{SEN}_{\text {lame }}$ and $\mathrm{SEN}_{\text {lesion }}$ values for observers and 3D-ALS are explained by an overestimation of lameness by 3D-ALS when compared with observers. Thus, comparable $\mathrm{SEN}_{\text {lame }}$ and $\mathrm{SEN}_{\text {lesion }}$ were reached at the expense high number of false positives and low $\mathrm{SPE}_{\text {nonlame }}$ and $\mathrm{SPE}_{\text {nonlesion. Considering that }}$ observers and 3D-ALS showed similar performance for classifying cows as lame and for detecting horn and combinations of skin/horn lesions, the 3D-ALS could be a useful tool for supporting dairy farmers in their hoof health management.

Key words: automatic detection, cattle, hoof lesion, lameness, locomotion score

\section{INTRODUCTION}

Lameness is considered a major welfare problem in modern dairy farms. Lameness is highly prevalent with an average prevalence of $37 \%$ in England and Wales (Barker et al., 2010), 33\% in Austria and Germany (Dippel et al., 2009), and from 21 to $55 \%$ in the United States (Cook, 2003; Espejo et al., 2006; von Keyser- 
lingk et al., 2012). Lameness has been associated with a reduced 305-d milk production (Warnick et al., 2001; Archer et al., 2010), a higher SCC (Archer et al., 2011), a decreased expression of estrus behavior (Walker et al., 2008), and a prolonged lapse between calving to first service and between first service and conception (Barkema et al., 1994).

Lameness is defined as impaired locomotion. The most used methods for lameness assessment in dairy cattle are manual locomotion scorings, which are procedures used to evaluate the quality of the locomotion of cows (Whay, 2002; Flower and Weary, 2009; SchlageterTello et al., 2014b). When scoring locomotion, observers focus their attention on gait and posture traits that are described in the protocol of the applied locomotion scoring method. Using these traits, observers assign a locomotion score to cows according to a pre-determined scale.

Hoof health management planning, in which locomotion scoring plays a crucial role, involves several steps. First, each cow is observed to evaluate gait and posture traits to assign a score for the quality of locomotion. This is usually done on a multilevel ordinal scale running from normal to severely impaired locomotion. Second, cows are classified as lame or nonlame when a predetermined threshold on the scale is exceeded, usually the middle level of the scale. It is commonly assumed that cows classified as lame suffer pain due to either hoof or other limb lesions (Flower and Weary, 2009; Schlageter-Tello et al., 2014b). Therefore, manual locomotion scoring methods are also used to detect hoof or other limb lesions (step 3). In this regard, manual locomotion scoring systems have been included in programs aimed at improving hoof health (DairyCo., 2007; Alberta Dairy Hoof Health Project, 2014) and animal welfare assessment protocols (University of Bristol, 2004; Welfare Quality, 2009). The final step within lameness management involves the choice between an appropriate treatment strategy or culling.

When using manual locomotion scoring methods to identify lameness, it is important that the locomotion scores assigned are reliable and consistent within and between observers under different practical conditions to create accurate and comparable records. In addition, if lameness is used as a visual sign for hoof lesions, it is important that cows classified as lame are indeed affected by hoof lesions. Recently, some studies questioned both the capability of human observers to perform locomotion scoring consistently and the utility of lameness for lesion detection (Engel et al., 2003; Tadich et al., 2010; Schlageter-Tello et al., 2014b).

In recent years, several automatic locomotion scoring systems have been developed due to the increasing number of animals per dairy farm and to the lack of time on the part of the farmers to monitor the increasing number of animals or to improve methods for better detection of lameness and hoof lesion (Rutten et al., 2013; Schlageter-Tello et al., 2014b; Van Nuffel et al., 2015). Most automatic locomotion scoring systems attempt to mimic human observers by measuring and analyzing parameters of cows' locomotion and behavior through sensors and mathematical algorithms. Some examples include measuring forces exerted on the floor by the limbs using force plates (Rajkondawar et al., 2002) or 3-dimensional (3D) force plates (Dunthorn et al., 2015), weight distribution of limbs using 4 independent weighing units (Chapinal et al., 2009a), parameters associated with distances between hoof prints using pressure-sensitive mats (Maertens et al., 2011), or parameters associated with activity and behavior using accelerometers attached to the neck or limbs of cows (Alsaaod et al., 2012; Thorup et al., 2015). Recently a promising approach for an automatic locomotion scoring used 3D camera technology to measure different angles associated with back curvature (Viazzi et al., 2013; Van Hertem et al., 2014). The advantages of the $3 \mathrm{D}$ computer vision automatic locomotion scoring system (3D-ALS) include utilization of a single sensor (1 camera) to assess locomotion in a large number of cows, the same set-up may be used to assess different parameters (e.g., BCS) and it shows acceptable performance for lameness detection (Viazzi et al., 2013; Van Hertem et al., 2014).

The 3D-ALS and most automatic locomotion scoring methods are evaluated for lameness detection using a locomotion score or lame/nonlame classification assigned from observers to a cow as a reference (Schlageter-Tello et al., 2014b). Most studies, however, comparing automatic and manual locomotion scoring report only the performance of the automatic systems compared with observers performing locomotion scoring, but do not report the performance of observers used as reference (Schlageter-Tello et al., 2014b). Similarly, few studies compare the performance of manual and automatic locomotion scoring systems with presence/absence of hoof lesions, and to our knowledge, only one article compared the performance of both manual and automatic locomotion scoring systems for detecting hoof lesions under the same practical conditions (Bicalho et al., 2007). Thus, an actual comparison between both systems for lameness assessment and hoof lesion detection has not yet been performed properly.

Given the lack of information when comparing both manual and automatic locomotion scoring, the objective of this study was to determine if a 3D-ALS was able to outperform human observers performing manual locomotion scoring for classifying cows as lame/nonlame and detecting specific types of hoof lesions. 


\section{MATERIALS AND METHODS}

\section{Animals, Housing, and Routine Hoof Care}

The experiment was carried out on a commercial dairy farm located in Flanders, Belgium. The number of cows in the milking herd ranged between 208 and 242 through the year. All cows belonged to the Holstein-Friesian breed and were housed all-year-round indoors in a freestall barn with slatted floors. Stalls had concrete flooring covered with rubber mattresses and bedded with a thin layer of wood shavings. The average 305-d milk production was 7,205 $\pm 1,842 \mathrm{~kg}$. The milking herd was divided into 2 production groups according to production level. The proportional group distribution was on average 3:2 (high:low). The cows were fed twice a day with a TMR composed mainly of corn and grass silage. Concentrate was provided by automatic feeders located in the barn. Water was available ad libitum. The cows were milked 2 times per day (0600 to $0830 \mathrm{~h}$ and 1800 to $2015 \mathrm{~h}$ ) in a 40-stand DeLaval rotary milking parlor (DeLaval, Tumba, Sweden). Prior to milking, both production groups were brought to the waiting area. An automated mechanic fence pushed the cows closer to the milking parlor. After milking, the cows stepped away from the rotary milking parlor, and entered a 20 -m-long single-lane alley that led them back to the cow shed. At the end of the alley, a spray box disinfected the udder and teats after milking, and a smart selection gate automatically divided the milking herd into the 2 production groups and separated cows from the herd for treatment.

The farmer performed several routine tasks to control hoof health in the herd. Hoof trimming was done weekly to approximately 10 cows. Cows were routinely selected for trimming at $100 \mathrm{~d}$ after calving, just before dry-off, and when observed as severely lame by the farmer. Each cow was hoof trimmed at least twice a year. During trimming, detected lesions were treated and hoof overgrowth was corrected. Once a week after morning milking, all cows passed a hoof bath filled with a $5 \%$ copper sulfate solution for digital dermatitis control.

\section{Experimental Sessions}

This paper reports the results obtained from 2 experimental sessions. The first experimental session was done in November 2013, whereas the second experimental session was done in April 2014. In each session, locomotion of all milked cows was scored manually and automatically. Additionally, all 4 hooves of all cows were checked for lesions by an experienced observer and trimmed by an experienced hoof trimmer. Each experimental session was performed on 2 consecutive days due to the high number of cows that needed to be hoof trimmed. A manual and automatic locomotion score were assigned to a cow on $\mathrm{d} 1$ of the experimental session after morning milking and before hoof trimming. Each cow received a single locomotion score from the human observer and from the 3D-ALS in an experimental session. In both sessions 270 different cows were locomotion scored and trimmed from which 223 cows were assessed both in experimental session 1 and session 2 (depending on routine farm management for dry-off and calving).

\section{Manual Locomotion Scoring}

Manual locomotion scoring was performed simultaneously by 2 experienced observers without further training together (Schlageter-Tello et al., 2014a, 2015b). The observers were positioned at the end of the 20-m-long single-lane alley behind the spray box, and locomotion was scored from a flank view perspective. Manual locomotion scoring was performed using a 5-level ordinal scale and was based on judging 4 gait and posture traits: namely, asymmetric gait, arched back, reluctance to bear weight, and head bobbing as described by Flower and Weary (2006). In short, cows that were scored at level 1 had a smooth and fluid gait and cows scored at level 5 had a severely restricted gait. A cow was classified as lame when locomotion score was $\geq 3$.

\section{D Computer Vision Automatic Locomotion Scoring}

The 3D-ALS used in this study used 3D computer vision techniques in a fully automatic setup as described by Van Hertem et al. (2016, 2017), which integrated the model measuring body movement pattern as described previously by Van Hertem et al. (2014) and Viazzi et al. (2014).

The 3D-ALS working process followed 4 steps: (1) video recording, (2) merging cow identification and video recording, (3) video filtering, and (4) video analysis. In step 1 (video recording), cows were recorded after every milking. Video recording was done with a Microsoft Kinect Xbox 3D camera (Kinect, Microsoft Corp., Redmond, WA) installed in top-down perspective at $3.45 \mathrm{~m}$ above ground level. The 3D-ALS was located approximately $10 \mathrm{~m}$ after the beginning of the single-lane alley leading from the rotary milking parlor to the shed. Each cow that entered the corridor passed a radiofrequency identification antenna (RFID-unit, DeLaval AB, Tumba, Sweden) that identified the cow and started the recording. The recording automatically stopped when a new cow was identified or if the photocell laser-beam of the RFID-unit was cut. Video recordings containing depth records were made at 30 
frames per second as .oni files. During step 2, a time sequence matching algorithm was used to associate individual identification of a cow to its respective video record. Merging cow identification with a video record was done comparing the timestamp of each cow passing the RFID-unit with the timestamp of the video record file. During step 3, poor quality video recordings were filtered out using the filtering procedure described by Romanini et al. (2013). Video recordings were filtered out when (1) multiple cows appeared in the video, (2) video did not have enough frames for analysis, and (3) videos containing an irregular cow gait (stop or run). After video recording, cow identification, merging, and filtering, the remaining videos were further analyzed and classified (step 4). The algorithm, described by Van Hertem et al. (2014) and Viazzi et al. (2014), automatically segmented the cow body in the images and extracted the cow's back spine contour line, based on the 3D coordinates and calculated the body movement pattern. The final body movement pattern was assigned a continuous value between 0 (nonlame cow) and 1 (extremely lame cow). A cow was classified as lame when the body movement pattern was $>0.334$ (range: 0.198-0.508). A locomotion score was assigned by the 3D-ALS using the average of body movement pattern values collected over the last $7 \mathrm{~d}$. At least 5 body movement pattern values (in $7 \mathrm{~d}$ ) were required to assign a locomotion score to a cow (Van Hertem et al., 2017).

The algorithm described by Van Hertem et al. (2014) and Viazzi et al. (2014) was calibrated to the new automatic and stationary setup and to the size of cows in the new experimental farm with data gathered between September 1, 2013, and November 1, 2013.

\section{Hoof Trimming and Lesion Identification}

Hoof trimming was done by 2 professional claw trimmers, each using a vertical trimming box located in the cow shed. During trimming, hoof lesions were identified and recorded by 2 observers (different persons than the trimmers). Each observer was positioned near the trim box to have a proper view of the hooves. In both experimental sessions the same observer and trimmer worked together. The identification of lesions was based on the guidelines proposed by the Alberta Dairy Hoof Health Project (2014) and described in Table 1. In each session each individual cow was assigned to only one group affected with the specific type(s) of lesions affecting that cow. The groups were as follows: no lesions, including cows without visible hoof lesions; skin, including cows affected by skin disruptions around hooves (i.e., digital or inter-digital dermatitis, or both); horn, including cows affected only by horn disruptions (i.e., horn ulcers, white line disease, axial fissure, or a combination of these); hyperplasia, including cows affected only by inter-digital hyperplasia; skin/horn, including cows affected simultaneously by skin and horn lesions; skin/ hyperplasia, including cows affected simultaneously by skin lesions and hyperplasia; and horn/hyperplasia, including cows simultaneously affected by horn lesions and hyperplasia. Due to low prevalence $(<5 \%)$, the hyperplasia and horn/hyperplasia groups were excluded from the statistical analysis. No cows were affected simultaneously by the 3 types of lesions. Lesions detected during trimming were treated and overgrowth was corrected.

\section{Statistical Analysis}

The performance of the manual locomotion scoring and 3D-ALS was estimated to (a) classify a cow as nonlame (0) or lame (1), and (b) detect cows nonaffected (0) or affected (1) by specific types of hoof lesions, namely, skin, horn, and combinations of skin/horn and skin/hyperplasia.

\section{Performance of Observers and 3D-ALS in Classifying a Cow as Lame and Nonlame}

Performance of observers and 3D-ALS in classifying a cow as lame or nonlame was evaluated by comparing classifications from both observers (Obs1-Obs2 comparison), and each observer with 3D-ALS (Obs-3D-

Table 1. Description of hoof lesions ${ }^{1}$

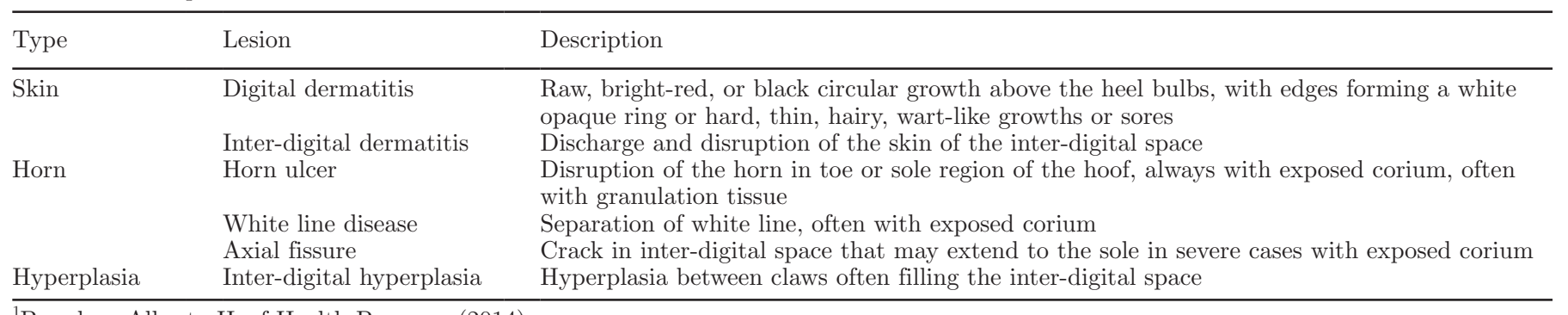

${ }^{1}$ Based on Alberta Hoof Health Program (2014). 
ALS comparison) using observer assessment as the gold standard. The gold standard provides the definition of a case or condition (e.g., lameness case) and is assumed as the true reference to evaluate the performance of a new diagnostic tool (Coggon et al., 2005). In a perfect world, the gold standard is a theoretical method or procedure that is absolutely valid and consistent (Dohoo et al., 2003). However, in reality the gold standard is the best or closest method available to determine a case or condition (Dohoo et al., 2003). The overall performance of observers and 3D-ALS for classifying cows as lame and nonlame was done calculating the following: percentage of agreement $\left(\mathbf{P A}_{\text {lame/nonlame }}\right)$, which indicates the percentage at which observers or 3D-ALS agree in classifying a cow as lame or nonlame; the kappa coefficient $\left(\kappa_{\text {lame}} /\right.$ nonlame $)$, which corrects PA by the expected agreement by chance and indicates the ability of observers or 3D-ALS to differentiate between categories on a binary scale (i.e., lame or nonlame; Kottner et al., 2011). Cross tables were also used to calculate the performance of observers and 3D-ALS for classifying lame cows as lame, expressed as sensitivity $\left(\mathbf{S E N}_{\text {lame }}\right)$; and the performance for classifying nonlame cows as nonlame expressed as specificity $\left(\mathbf{S P E} \mathbf{E}_{\text {nonlame }}\right)$. For the Obs1-Obs2 comparison, $\mathrm{SEN}_{\text {lame }}$ and $\mathrm{SPE}_{\text {nonlame }}$ were equivalent to the percentage of positive and negative agreement described by Cicchetti and Feinstein (1990). For Obs-3D-ALS comparisons, $\mathrm{SEN}_{\text {lame }}$ and $\mathrm{SPE}_{\text {nonlame }}$ were calculated twice using a different observer each time as the gold standard. Values for $\kappa$ are usually classified as poor $(\kappa<0.4)$, moderate $(\kappa=0.4-0.6)$, acceptable $(\kappa=0.6-0.8)$, and excellent $(\kappa>0.8)$, whereas acceptable values for PA, SEN, and SPE were set at $>75 \%$ (Landis and Koch, 1977; Burn and Weir, 2011). The 95\% Clopper-Pearson confidence intervals (95\% confidence intervals) were calculated for $\mathrm{PA}_{\text {lame/nonlame, }}$, $\kappa_{\text {lame/nonlame }}, \mathrm{SEN}_{\text {lame }}$, and $\mathrm{SPE}_{\text {nonlame }}$.

A generalized linear mixed model in logistic scale was used to estimate the probability for classifying a cow as lame. The models comprised the fixed effects of observers (observer 1, 2, or 3D-ALS), session (experimental sessions 1 and 2), parity number (1st, 2nd, or $\geq 3 \mathrm{rd}$ ), 4 types of lesions affecting individual cows (skin, horn, skin/horn, and skin/hyperplasia), and the observer $\times$ session interaction. For each fixed effect the following estimates were calculated: the mean estimates (as least squares means); the level of significance, which was established at $P<0.05$; the F-test value divided by the degrees of freedom (F-test/df), which indicates the relative size of the fixed effect explaining the variability on the dependent variable; and odds ratios representing the odds that an outcome will occur given a particular condition compared with the odds of the outcome occurring in a different condition (e.g., odds of being lame in 1st vs. 2nd or 1st vs. 3rd parity; Hosmer and Lemeshow, 2000). The intercept and cow were included as random effects.

\section{Performance of Observers and 3D-ALS in Detecting Different Types of Hoof Lesions}

The overall performance of observers and 3D-ALS in detecting different types of hoof lesions when a cow was classified as lame or a cow without lesions classified as nonlame was estimated using cross-tables and by calculating $\mathrm{PA}_{\text {lesion/nonlesion, }}$ indicating the percentage at which an observer (or 3D-ALS) detected a cow affected or nonaffected by a type of hoof lesion when classified as lame or nonlame, respectively; and the $\kappa$ coefficient $\left(\kappa_{\text {lesion/nonlesion }}\right)$, indicating the ability of observers (or 3D-ALS) to differentiate between a cow affected or nonaffected by a type of lesion when a cow was classified as lame or nonlame, respectively. Cross-tables were also used to calculate the performance of observers and 3D-ALS for detecting type(s) of lesions when a cow was classified as lame expressed as sensitivity $\left(\mathrm{SEN}_{\text {lesion }}\right)$ and the performance for detecting cows without hoof lesions when a cow was classified as nonlame expressed as specificity $\left(\mathrm{SPE}_{\text {nonlesion }}\right)$. The $95 \%$ confidence interval were calculated for $\mathrm{PA}_{\text {lesion/nonlesion, }} \kappa_{\text {lesion/nonlesion, }}$ $\mathrm{SEN}_{\text {lesion, }}$ and $\mathrm{SPE}_{\text {nonlesion. All estimations involving }}$ cross-tables were calculated using FREQ procedure in SAS 9.3 (SAS Institute Inc., Cary, NC).

To estimate differences in probability for detecting different types of hoof lesions, 4 generalized linear mixed models using a logistic scale were used. The 4 models estimated the probability of a cow being affected by type(s) of lesions (i.e., skin, horn, horn/skin, and skin/ hyperplasia). The fixed effect for these models were session (experimental session 1 or 2), parity number (parity 1,2 , or $\geq 3$ ), and the interaction between observer $\times$ lameness classification (which indicated the probability of observers or 3D-ALS detecting a cow with a type of lesion when a cow was classified as lame). For each fixed effect the mean estimates, the level of significance, the F-test/df, and the odds ratio were calculated. Intercept and cow were included as random effect. All generalized general linear mixed models were created using the GLIMMIX procedure in SAS 9.3 (SAS Institute Inc., Cary, NC).

\section{RESULTS}

\section{Locomotion Scores and Lameness Prevalence}

Table 2 shows the relative distribution of a 5-level locomotion score and lame or nonlame classification assigned by observers and 3D-ALS. In both sessions, 
Table 2. Relative distribution of cows scored with a 5-level locomotion score and lame or nonlame classification (lame $\geq$ level 3) performed by 2 human observers (Obs1 and Obs2) and a 3-dimensional computer vision automatic locomotion score (3D-ALS) in 2 sessions

\begin{tabular}{|c|c|c|c|c|c|c|c|c|c|}
\hline \multirow[b]{2}{*}{ Session } & \multirow[b]{2}{*}{ Observer } & \multirow[b]{2}{*}{$\mathrm{n}$} & \multicolumn{5}{|c|}{ Level (\%) } & \multicolumn{2}{|c|}{ Level (\%) } \\
\hline & & & 1 & 2 & 3 & 4 & 5 & Nonlame & Lame \\
\hline \multirow[t]{3}{*}{1} & Obs1 & 213 & 11.3 & 54.0 & 22.1 & 10.8 & 1.9 & 65.3 & 34.7 \\
\hline & Obs2 & 216 & 24.1 & 42.1 & 23.1 & 7.9 & 2.8 & 66.2 & 33.8 \\
\hline & 3D-ALS & 171 & 8.2 & 39.8 & 36.3 & 12.9 & 2.9 & 48.0 & 52.0 \\
\hline \multirow[t]{3}{*}{2} & Obs1 & 233 & 22.7 & 50.6 & 21.5 & 5.2 & 0.0 & 73.4 & 26.6 \\
\hline & Obs2 & 234 & 23.9 & 36.3 & 27.8 & 10.3 & 1.7 & 60.3 & 39.7 \\
\hline & 3D-ALS & 165 & 19.4 & 41.2 & 29.7 & 9.1 & 0.6 & 60.6 & 39.4 \\
\hline
\end{tabular}

fewer cows were assessed by the 3D-ALS than by the observers (Table 2).

A large variation was present in the number of cows classified as lame by both observers and 3D-ALS in each session. In session 1, 3D-ALS had a higher lameness prevalence than both observers (Table 2). In session 2, Obs2 and 3D-ALS had a higher lameness prevalence than Obs1 (Table 2).

\section{Hoof Lesion Prevalence}

Identified hoof lesions and their relative distribution are shown in Table 3. The percentage of cows affected by at least one type of lesion was 77.3 and $63.9 \%$ in session 1 and 2, respectively. Most cows were affected by skin lesion or a combination of skin/horn or of skin/ hyperplasia lesions (Table 3 ).

\section{Performance of Observers and 3D-ALS in Classifying Cows as Lame or Nonlame}

Table 4 shows the performance of both observers and 3D-ALS in classifying cows as lame and nonlame. In general, observers showed a better overall ability for classifying cows as lame or nonlame than 3D-ALS as Obs1-Obs2 comparison had higher $\mathrm{PA}_{\text {lame/nonlame }}$ and $\kappa_{\text {lame/nonlame }}$ than both Obs/3D-ALS comparisons (Table 4). Similarly, 95\% confidence interval shows that Obs1-
Obs2 comparison had higher $\mathrm{SPE}_{\text {nonlame }}$ than Obs-3DALS comparison, indicating that observers performed better when classifying a cow as nonlame than 3D-ALS. However, Obs1-Obs2 and Obs-3D-ALS comparisons showed similar $\mathrm{SEN}_{\text {lame }}$ values, indicating no difference in the performance of classifying cows as lame when observers and 3D-ALS were compared. The $95 \%$ confidence intervals showed no differences for $\mathrm{PA}_{\text {lame/nonlame }}$, $\kappa_{\text {lame/nonlame, }}, \mathrm{SEN}_{\text {lame }}$, and $\mathrm{SPE}_{\text {nonlame }}$ in sessions 1 and 2 for Obs1, Obs2, and 3D-ALS (data not shown).

\section{Probability for Classifying a Cow as Lame}

Table 5 shows the results of the generalized mixed model to estimate the probability for classifying a cow as lame. Based on $P$-values and $\mathrm{F}$-value/df, fixed effects affecting the probability for classifying a cow as lame were parity number, observer, and the interaction between observer and session and presence of horn and skin/horn lesions (Table 5).

Odds ratio for the probability of classifying cows as lame increased with increasing parity number (Table $5)$. The odds ratio for the interaction between observer and session shows that, Obs2 had lower probabilities for classifying a cow as lame in session 1 than in session 2 (Table 5). Cows affected with horn and horn/skin lesions had higher probabilities of being classified as lame (Table 5).

Table 3. Relative distribution for different types of hoof lesions ${ }^{1}$ found in 2 experimental sessions ( $\operatorname{session~} 1, \mathrm{n}=233$; session 2 , n $=244$ )

\begin{tabular}{lcccccccc}
\hline Session & $\begin{array}{c}\text { No lesions } \\
(\%)\end{array}$ & $\begin{array}{c}\text { Skin } \\
(\%)\end{array}$ & $\begin{array}{c}\text { Horn } \\
(\%)\end{array}$ & $\begin{array}{c}\text { Hyperplasia } \\
(\%)\end{array}$ & $\begin{array}{c}\text { Skin/horn } \\
(\%)\end{array}$ & $\begin{array}{c}\text { Skin/hyperplasia } \\
(\%)\end{array}$ & $\begin{array}{c}\text { Horn/hyperplasia } \\
(\%)\end{array}$ & $\begin{array}{c}\text { Total affected } \\
(\%)\end{array}$ \\
\hline 1 & 22.7 & 42.9 & 10.7 & 1.3 & 13.7 & 7.3 & 1.3 & 77.3 \\
2 & 36.1 & 39.3 & 6.6 & 0.8 & 7.8 & 8.2 & 1.2 & 63.9 \\
\hline
\end{tabular}

${ }^{1}$ Skin: includes cows only affected by digital/inter-digital dermatitis; horn: includes cows affected only by horn disruptions (i.e., horn ulcers, white line disease, axial fissure, or a combination of these); hyperplasia: includes cows only affected by inter-digital hyperplasia; skin/horn: includes cows affected simultaneously by digital/inter-digital dermatitis and horn lesions; skin/hyperplasia: includes cows affected simultaneously by digital/inter-digital dermatitis and inter-digital hyperplasia; horn/hyperplasia: includes cows simultaneously affected by horn lesions and inter-digital hyperplasia.

${ }^{2}$ Indicates $\%$ of cows being affected by at least one type of lesion. 
Table 4. Performance of 2 observers (Obs1 and Obs2) and a 3-dimensional computer vision automatic locomotion scoring system (3D-ALS) to classify cows as lame or nonlame expressed as kappa coefficient $\left(\kappa_{\text {lame/nonlame }}\right)$, percentage of agreement $\left(\mathrm{PA}_{\text {lame} / \text { nonlame }}\right)$, specificity $\left(\mathrm{SPE}_{\text {nonlame }}\right)$, and sensitivity $\left(\mathrm{SEN}_{\text {lame }}\right)$

\begin{tabular}{|c|c|c|c|c|c|}
\hline Comparison & $\mathrm{n}$ & 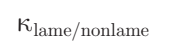 & $\mathrm{PA}_{\text {lame/nonlame }}(\%)$ & $\mathrm{SPE}_{\text {nonlame }}(\%)$ & $\mathrm{SEN}_{\text {lame }}(\%)$ \\
\hline Obs1-3D-ALS & 344 & $\begin{array}{l}0.33 \\
(0.23-0.42)\end{array}$ & $\begin{array}{l}67.7 \\
(62.7-72.7)\end{array}$ & $\begin{array}{l}65.3 \\
(59.1-71.2)\end{array}$ & $\begin{array}{l}73.9 \\
(64.0-82.7)\end{array}$ \\
\hline Obs2-3D-ALS & 344 & $\begin{array}{l}0.36 \\
(0.27-0.46)\end{array}$ & $\begin{array}{l}69.2 \\
(64.3-74.1)\end{array}$ & $\begin{array}{l}67.8 \\
(61.3-73.8)\end{array}$ & $\begin{array}{l}71.8 \\
(62.7-79.7)\end{array}$ \\
\hline
\end{tabular}

${ }^{1}$ Values in parentheses indicate $95 \%$ CI.

\section{Performance of Observers and 3D-ALS in Detecting Hoof Lesions}

Table 6 shows the performance of both observers and 3D-ALS in detecting specific type(s) of hoof lesions. In general, observers had poor overall performance for detecting skin lesions and a combination of skin/ hyperplasias $\left(\kappa_{\text {lesion/nonlesion }}<0.4\right.$ and $\mathrm{PA}_{\text {lesion/nonlesion }}$ $<75 \%$ ) and moderate overall performance for detect- ing horn lesions and combinations of horn/skin lesions $\left(\kappa_{\text {lesion} / \text { nonlesion }}=0.4-0.6\right.$ and $\mathrm{PA}_{\text {lesion/nonlesion }}>75 \%$; Table 6 ). The 3D-ALS showed poor overall performance for detecting skin and horn lesions, and combinations of skin/horn lesions and skin/hyperplasia ( $\kappa_{\text {lesion/nonlesion }}$ $<0.4$ and $\mathrm{PA}_{\text {lesion/nonlesion }}<75 \%$, Table 6 ).

The $95 \%$ confidence interval indicated that observers had a better $\mathrm{SPE}_{\text {nonlesion }}$ than 3D-ALS for detecting cows nonaffected by skin and horn lesions and a com-

Table 5. $P$-value, F-value divided by degrees of freedom (F-value/df), estimate, and odds ratio for 6 fixed effects used to estimate the probability of classifying a cow as lame

\begin{tabular}{|c|c|c|c|c|}
\hline Fixed effect & $P$-value & F-value/df & Estimate & $\begin{array}{c}\text { Odds } \\
\text { ratio }(95 \% \mathrm{CI})\end{array}$ \\
\hline Parity number & $<0.001$ & 8.5 & & \\
\hline 1 & & & 0.05 & 1 \\
\hline 2 & & & 0.73 & $1.9(1.3-3.1)$ \\
\hline$\geq 3$ & & & 1.44 & $4.0(2.5-6.4)$ \\
\hline Observer ${ }^{1}$ & 0.002 & 3.3 & & \\
\hline Obs1 & & & 0.38 & 1 \\
\hline Obs2 & & & 0.69 & $1.4(0.9-1.9)$ \\
\hline 3D-ALS & & & 1.14 & $2.1(1.4-3.3)$ \\
\hline Observer $\times$ session $^{2}$ & 0.05 & 1.5 & & \\
\hline Obs1, session 1 vs. 2 & & & 0.29 & $1.3(0.8-2.3)$ \\
\hline Obs 2 , session 1 vs. 2 & & & -0.45 & $0.6(0.4-1.1)$ \\
\hline 3D-ALS, session 1 vs. 2 & & & 0.54 & $1.7(0.9-3.3)$ \\
\hline Horn $^{3}$ & 0.003 & 9.2 & & \\
\hline Absent & & & 0.004 & 1 \\
\hline Affected & & & 1.48 & $4.3(1.7-11.3)$ \\
\hline Skin/horn ${ }^{3}$ & 0.02 & 5.1 & & \\
\hline Absent & & & 0.33 & 1 \\
\hline Affected & & & 1.15 & $2.3(1.1-4.6)$ \\
\hline Skin/hyperplasia ${ }^{3}$ & 0.07 & 3.4 & & \\
\hline Absent & & & 0.38 & 1 \\
\hline Affected & & & 1.10 & $2.1(0.9-4.5)$ \\
\hline Skin $^{3}$ & 0.62 & 0.25 & & \\
\hline Absent & & & 0.69 & 1 \\
\hline Affected & & & 0.79 & $1.1(0.7-1.7)$ \\
\hline Session & 0.48 & 0.5 & & \\
\hline 1 & & & 0.80 & 1 \\
\hline 2 & & & 0.68 & $0.9(0.6-1.3)$ \\
\hline
\end{tabular}

${ }^{1}$ Obs1 $=$ observer $1 ;$ Obs2 $=$ observer $2 ; 3$ D-ALS $=3$-dimensional computer vision automatic locomotion scoring system.

${ }^{2}$ Indicates the probability of observers or 3D-ALS for classifying a cow as lame in session 1 vs. session 2. Odds ratios were calculated using session 2 as reference.

${ }^{3}$ Skin: includes cows only affected by digital/inter-digital dermatitis; horn: includes cows affected only by horn disruptions (i.e., horn ulcers, white line disease, axial fissure, or a combination of these); skin/horn: includes cows affected simultaneously by digital/inter-digital dermatitis and horn lesions; skin/hyperplasia: includes cows affected simultaneously by digital/inter-digital dermatitis and inter-digital hyperplasia. 
Table 6. Performance of 2 observers (Obs1 and Obs2) and a 3-dimensional computer vision automatic locomotion scoring system (3D-ALS) to detect different types of hoof expressed as kappa coefficient $\left(\kappa_{\text {lesion/nonlesion }}\right)$, percentage of agreement $\left(\mathrm{PA}_{\text {lesion/nonlesion }}\right)$, specificity $\left(\mathrm{SPE}_{\text {nonlesion }}\right)$, and sensitivity $\left(\mathrm{SEN}_{\text {lesion }}\right)$

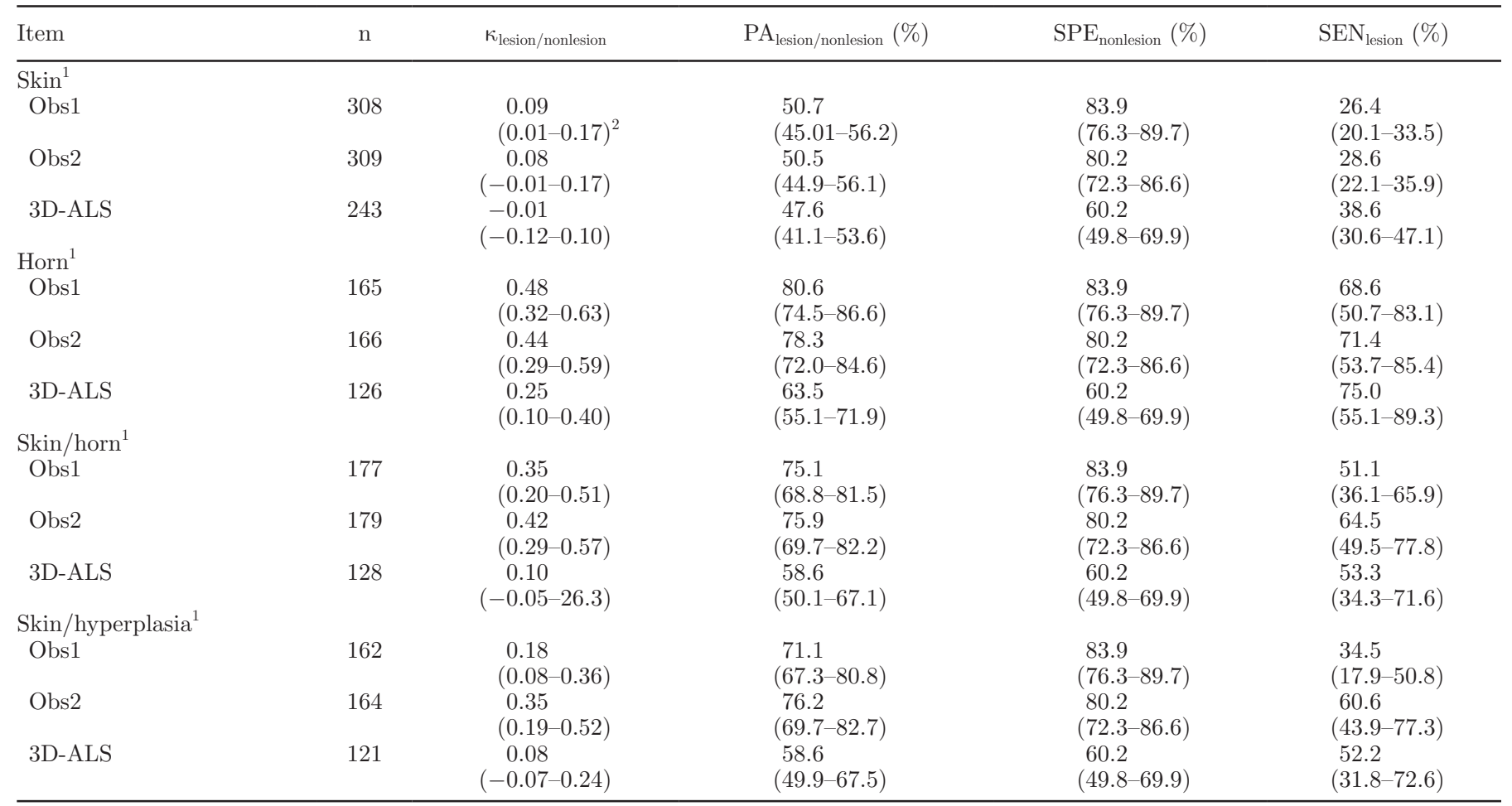

${ }^{1}$ Skin: includes cows only affected by digital/inter-digital dermatitis; horn: includes cows affected only by horn disruptions (i.e., horn ulcers, white line disease, axial fissure, or a combination of these); skin/horn: includes cows affected simultaneously by digital/inter-digital dermatitis and horn lesions; skin/hyperplasia: includes cows affected simultaneously by digital/inter-digital dermatitis and inter-digital hyperplasia.

${ }^{2}$ Values in parentheses indicate $95 \%$ CI.

bination of skin/horn lesions. However, for all types of hoof lesions, $\mathrm{SEN}_{\text {lesion }}$ did not differ between observers and 3D-ALS (Table 6). Both, observers and 3D-ALS showed a higher $\mathrm{SEN}_{\text {lesion }}$ when detecting horn lesions and a combination of skin/horn lesions than for skin lesions and a combination of skin/hyperplasias (Table 6). The $95 \%$ confidence intervals showed no differences for $\mathrm{PA}_{\text {lesion/nonlesion, }}, \kappa_{\text {lesion/nonlesion, }}, \mathrm{SEN}_{\text {lesion }}$, and $\mathrm{SPE}_{\text {nonlesion }}$ in sessions 1 and 2 for Obs1, Obs2, and 3D-ALS (data not shown).

\section{Probability of a Cow Being Affected by Different Types of Hoof Lesions}

Table 7 shows the results of the 4 generalized mixed models for estimating the probability of a cow being affected by skin lesions, horn lesions, and combinations of skin/horn lesions, and skin/hyperplasias. Based on both $P$-value and $\mathrm{F}$-values/df, the fixed effects determining the probability of a cow being affected by horn and skin lesions were session and parity. Session was the only fixed effect that significantly affected the probability of a cow being affected by a combination of skin/horn lesions (Table 7).
Odds ratios showed lower probabilities for being affected by horn lesions, skin lesions, and a combination of skin/horn lesions in session 2 than in session 1 (Table 7). The probability of a cow being affected by horn lesions was significantly higher for parity $\geq 3$ than parity 1 and 2. For skin lesions, odds ratios for parity number 2 were higher than for parity number 1 and 3 (Table 7).

\section{DISCUSSION}

In the current experiment observer performance for classifying cows lame and nonlame was good $\left(\mathrm{PA}_{\text {lame} / \text { nonlame }}>75 \% ; \kappa_{\text {lame/nonlame }}>0.6 ; \mathrm{SEN}_{\text {lame }}=74 \%\right.$; $\mathrm{SPE}_{\text {nonlame }}>75 \%$ ) and comparable to results reported previously for experienced observers as reported by Winckler and Willen (2001; $\mathrm{PA}_{\text {lame/nonlame }}=91 \%$; $\kappa_{\text {lame } / \text { nonlame }}=0.69 ; \mathrm{SEN}_{\text {lame }}=75 \%$; and $\mathrm{SPE}_{\text {nonlame }}=$ $95 \%)$, Schlageter-Tello et al. (2014a; $\mathrm{PA}_{\text {lame/nonlame }}=$ $85 \% ; \kappa_{\text {lame } / \text { nonlame }}=0.7 ; \mathrm{SEN}_{\text {lame }}=85 \%$; and $\mathrm{SPE}_{\text {nonlame }}=$ $85 \%)$, and Schlageter-Tello et al. $\left(2015 \mathrm{~b} ; \mathrm{PA}_{\text {lame/nonlame }}=\right.$ $82 \% ; \kappa_{\text {lame } / \text { nonlame }}=0.52 ; \mathrm{SEN}_{\text {lame }}=63 \%$; and $\mathrm{SPE}_{\text {nonlame }}$ $=88 \%)$. Although training could have improved the performance of observers in the current experiment (March et al., 2007; Vasseur et al., 2013), we believe 
that using experienced observers without common training is in agreement with most practical situations in which assessors working in hoof health are experienced but not commonly trained.

The 3D-ALS had a lower overall performance for classifying cows as lame or nonlame when compared with observers (as reflected in higher $\mathrm{PA}_{\text {lame/nonlame, }}$ $\kappa_{\text {lame/nonlame, }}$ and $\mathrm{SPE}_{\text {nonlame }}$ values for Obs1-Obs2 com- parison than for Obs-3D-ALS comparison). Lower performance of the 3D-ALS when compared with observers can be partially explained by differences in traits used by observers and 3D-ALS. Whereas observers assigned a locomotion score judging several gait and posture traits, 3D-ALS was exclusively based on measurement of back curvature. When a score based solely on back curvature was compared with a conventional locomo-

Table 7. $P$-value, F-value divided by degrees of freedom (F-value/df), estimate, and odds ratio for fixed effects used to estimate the probability that cows developed different type(s) of hoof lesions

\begin{tabular}{|c|c|c|c|c|}
\hline Fixed effect & $P$-value & F-value/df & Estimate & $\begin{array}{c}\text { Odds ratio } \\
(95 \% \mathrm{CI})\end{array}$ \\
\hline \multicolumn{5}{|l|}{$\overline{\text { Skin }^{1}}$} \\
\hline Session & $<0.001$ & 17.6 & & \\
\hline 1 & & & 1.18 & 1 \\
\hline 2 & & & 0.27 & $0.4(0.3-0.6)$ \\
\hline Parity number & 0.02 & 2.1 & & \\
\hline 1 & & & 0.44 & 1 \\
\hline 2 & & & 1.56 & $3.1(1.2-7.6)$ \\
\hline$\geq 3$ & & & 0.17 & $0.8(0.3-1.9)$ \\
\hline Observer $\times$ lameness & 0.47 & 0.18 & & \\
\hline Obs1 & & & 0.81 & 1 \\
\hline Obs2 & & & 1.23 & $0.7(0.3-1.8)$ \\
\hline $3 \mathrm{D}-\mathrm{ALS}^{2}$ & & & 0.65 & $1.2(0.4-3.2)$ \\
\hline \multicolumn{5}{|l|}{ Horn $^{1}$} \\
\hline Session & 0.0002 & 14.4 & & \\
\hline 1 & & & -1.21 & 1 \\
\hline 2 & & & -2.85 & $0.2(0.09-0.5)$ \\
\hline Parity number & 0.0007 & 3.7 & & \\
\hline 1 & & & -2.90 & 1 \\
\hline 2 & & & -2.69 & $1.2(0.2-7.3)$ \\
\hline$\geq 3$ & & & -0.51 & $10.9(2.8-41.1)$ \\
\hline Observer $\times$ lameness & 0.07 & 0.41 & & \\
\hline Obs1 & & & -1.11 & 1 \\
\hline Obs2 & & & -1.19 & $1.1(0.3-3.6)$ \\
\hline 3D-ALS & & & -1.72 & $1.8(0.5-6.2)$ \\
\hline \multicolumn{5}{|l|}{ Skin/horn ${ }^{1}$} \\
\hline Session & $<0.001$ & 16.1 & & \\
\hline 1 & & & -0.36 & 1 \\
\hline 2 & & & -2.19 & $0.2(0.06-0.4)$ \\
\hline Parity number & 0.22 & 0.75 & & \\
\hline 1 & & & -1.81 & 1 \\
\hline 2 & & & -1.35 & $1.5(0.4-7.1)$ \\
\hline$\geq 3$ & & & -0.67 & $3.1(0.9-11.4)$ \\
\hline Observer $\times$ lameness & 0.20 & 0.29 & & \\
\hline Obs1 & & & -0.47 & 1 \\
\hline Obs2 & & & -0.41 & $0.9(0.3-3.4)$ \\
\hline 3D-ALS & & & -1.22 & $2.1(0.5-8.9)$ \\
\hline \multicolumn{5}{|l|}{ Skin/hyperplasia $^{1}$} \\
\hline Session & 0.86 & 0.03 & & \\
\hline 1 & & & -1.99 & 1 \\
\hline 2 & & & -2.09 & $0.9(0.3-2.8)$ \\
\hline Parity number & 0.11 & 1.07 & & \\
\hline 1 & & & -2.91 & 1 \\
\hline 2 & & & -1.23 & $5.4(1.1-26.5)$ \\
\hline$\geq 3$ & & & -1.99 & $2.5(0.5-12.1)$ \\
\hline Observer $\times$ lameness & 0.67 & 0.13 & & \\
\hline Obs1 & & & -1.49 & 1 \\
\hline Obs2 & & & -1.31 & $0.8(0.1-4.9)$ \\
\hline $3 \mathrm{D}-\mathrm{ALS}$ & & & -2.09 & $1.8(0.3-12.4)$ \\
\hline
\end{tabular}

${ }^{1}$ Skin: includes cows only affected by digital/inter-digital dermatitis; horn: includes cows affected only by horn disruptions (i.e., horn ulcers, white line disease, axial fissure, or a combination of these); skin/horn: includes cows affected simultaneously by digital/inter-digital dermatitis and horn lesions; skin/hyperplasia: includes cows affected simultaneously by digital/inter-digital dermatitis and inter-digital hyperplasia.

${ }^{2} 3 \mathrm{D}$-ALS $=3$-dimensional automatic locomotion scoring method. 
tion score (used as gold standard), the back curvature score obtained a $\mathrm{SEN}_{\text {lame }}$ ranging from 44 to $58 \%$ and a $\mathrm{SPE}_{\text {nonlame }}$ ranging from 83 to $89 \%$ (Thomsen, 2009). Although back curvature is a widely accepted indicator of lameness (Schlageter-Tello et al., 2014b, 2015a), it has been reported that not all lame cows show an arched back and that many cows classified as nonlame show it as well (Chapinal et al., 2009b; Thomsen, 2009). Differences in performance between observers and 3D-ALS can also be explained by technical limitations associated with the 3D-ALS such as narrow view angle of the $3 \mathrm{D}$ camera and cow traffic problems as discussed later.

The 3D-ALS had higher probabilities for classifying cows as lame when compared with Obs1 and showed higher lameness prevalence than both observers. These results suggest that 3D-ALS overestimated lameness when compared with human observers. Lameness overestimation by 3D-ALS explains similar performance for classifying lame cows by observers and 3D-ALS as reflected by similar $\mathrm{SEN}_{\text {lame }}$ values for Obs1-Obs2 and Obs-3D-ALS comparisons. Because 3D-ALS tended to classify more cows as lame than observers, the chances for agreeing with observers on classifying a cow as lame increased. These high $\mathrm{SEN}_{\text {lame }}$ values from 3D-ALS were reached at the cost of having a high number of false positives as suggested by low $\kappa_{\text {lame/nonlame }}$ and $\mathrm{SPE}_{\text {nonlame }}$ values for Obs-3D-ALS comparisons. However, overestimation of lameness by 3D-ALS was a rational decision by model developers aiming to maximize the detection of true positive cows in detriment of detection of true negatives. Another explanation for lameness overestimation could be related to cow crowding at the end of milking (Van Hertem et al., 2017). Crowding could create alteration in cow posture, which could increase back curvature and body movement pattern values, leading to lameness overestimation.

Previous versions of the described 3D-ALS showed a large variation in its performance for classifying cows as lame or nonlame when compared with observers. For instance, using a mobile 2-dimensional camera from flank perspective, a person controlling cow traffic, manual selection of video records, and manual measurement of the body movement pattern, Viazzi et al. (2013) reported a $\mathrm{PA}_{\text {lame } / \text { nonlame }}=85 \% ; \mathrm{SEN}_{\text {lame }}=76 \%$; $\mathrm{SPE}_{\text {nonlame }}=91 \%$. Using a mobile 3D camera set up from top-down perspective, a person controlling cow traffic, manual selection of video records and automatic measurement of the body movement pattern, Van Hertem et al. (2014) reported a $\mathrm{PA}_{\text {lame } / \text { nonlame }}=81 \%$; $\mathrm{SEN}_{\text {lame }}=55 \% ;$ and $\mathrm{SPE}_{\text {nonlame }}=90 \%$. Finally, using the same experimental setup as in the current manuscript, Van Hertem et al. (2016) reported $\mathrm{PA}_{\text {lame/nonlame }}$ $=69 \% ; \mathrm{SEN}_{\text {lame }}=48 \%$; and $\mathrm{SPE}_{\text {nonlame }}=83 \%$. Differ- ences in $\mathrm{PA}_{\text {lame/nonlame }}, \mathrm{SEN}_{\text {lame, }}$, and $\mathrm{SPE}_{\text {nonlame }}$ values in articles using similar computer-vision locomotion scoring systems could be explained by differences in body movement pattern cut-off threshold to classify cows as lame or nonlame. However, body movement pattern values and cut-off thresholds in different articles cannot be directly compared. Van Hertem et al. (2014) reported body movement pattern values ranging from 0.13 to 0.33 and a cut-off threshold for lameness classification $>0.21$. Differences in body movement pattern values from Van Hertem et al. (2014) and the current manuscript could be explained by differences in the position of the 3D camera (height and angle) and by the different size of cows used to develop the model. Cut-off threshold in the current manuscript can neither be compared with the values from Van Hertem et al. (2016), who performed a 10-fold cross-validation. The procedure for 10-fold cross-validation divides the data set in 10 equal parts. Then 9 parts are used to build the model, and 1 part to evaluate and test the model, repeating the process 10 times. Hence, it is not possible to calculate a fixed cut-off threshold. In addition the output of the 10-fold cross-validation was an average of $\mathrm{SEN}_{\text {lame}}, \mathrm{SPE}_{\text {nonlame, }}$ and $\mathrm{PA}_{\text {lame/nonlame, which did }}$ not necessarily correspond to the best possible model. Another explanation of variation in similar computer vision systems is related to specific protocols for development and validation in different articles. Viazzi et al. (2013) used a single video recording to calculate a body movement pattern in a cow. Two-thirds of the data set (223 video records of 90 different cows) was used for model developed and one-third for model validation. Van Hertem et al. (2014) used 4 consecutive measurements (4 video recordings on 4 consecutive days per cow) to assign a body movement pattern to a cow. Video recordings were selected based on the condition that 4 consecutive locomotion scores (assigned by an observer) did not vary more than 1 numerical unit to reduce human errors in the reference. Two-thirds of the data set (780 video records of 195 different cows) was used for model development and one-third for model validation. As previously explained, Van Hertem et al. (2016) performed a 10-fold cross-validation using a data set containing 1,327 video records of 511 different cows collected over 10 mo. This cross-validation aimed to discriminate between several indicators (i.e., body movement pattern vs. activity vs. production) over 10 mo. This 10-fold cross-validation aimed to select the best parameters for lameness detection (i.e., body movement pattern vs. activity vs. production data) and not to develop the best possible model for lameness detection. A final source for variation in the performance of similar computer-vision locomotion scoring systems is related to an increased automation. Systems using 
manual processes to control cow traffic, video recording, and video selection (i.e., Viazzi et al., 2013; Van Hertem et al., 2014) presented better overall performance than systems using a fully automatic process (current manuscript and Van Hertem et al., 2016). Better performance of manual over automatic setup could be explained by a better cow traffic and selection of better quality video recordings to perform analysis (i.e., cow walking one by one and a steady walking speed).

Automation of the 3D-ALS presented several practical issues that were in part solved by the decision to deliver a weekly locomotion score using the average of at least 5 body movement patterns from a cow (Van Hertem et al., 2017). First, if a single recording session was used, few cows were assigned with a locomotion score by 3D-ALS. According to Van Hertem et al. (2017), in a single recording session, from $100 \%$ of cows identified by the RFID-unit, only $49.3 \%$ of cows were assigned a locomotion score by the 3D-ALS. Most video recordings excluded from analysis were filtered out due to cow crowding at the end of milking. Using the average of 5 body movement pattern values allowed a locomotion score of $79.4 \%$ of cows to be assigned weekly (Van Hertem et al., 2017). Although 3D-ALS still assessed fewer cows than observers, we believe that 3D-ALS scored a sample big enough (about $75 \%$ of cows) for lameness prevalence from observers and 3D-ALS to be compared (Main et al., 2010). Second, the decision to use the average of at least 5 body movement patterns to assign a weekly locomotion score was made to overcome the technical limitations of 3D cameras. The Kinect camera had a recording speed of 30 frames and a narrow view angle ( $43^{\circ}$ vertical angle and $57^{\circ}$ wide angle). Thus, there was a relatively low number of frames (on average 5 frames) in which the view of the back of the cow was complete enough to be analyzed and to be assigned a locomotion score (Van Hertem et al., 2014). Because a relatively low number of frames per video was used to assign a locomotion score, there was a large variation in body movement pattern values in different sessions, leading to variation in locomotion scores assigned by 3D-ALS. Variation in body movement patterns in different sessions is reflected in values reported from Van Hertem et al. (2014). When body movement patterns of 4 consecutive days were considered independent observations, $\mathrm{PA}_{\text {lame/nonlame }}$ ranged between 42 and $53 \%$. When body movement pattern of 4 consecutive days was considered consecutive measurements of the same cow, $\mathrm{PA}_{\text {lame/nonlame }}$ increased with values ranging from 56 to $60 \%$. Thus, variation in body movement patterns in consecutive sessions was mitigated partially by the decision to deliver a locomotion score every $7 \mathrm{~d}$ using the average of at least 5 body movement patterns. Finally, the decision to deliver a weekly locomotion score per cow was done keeping in mind a possible final commercial product. Because farmers have a limited amount of time to dedicate to hoof health, the idea of providing a weekly locomotion score was taken to deliver manageable amounts of information to producers (check, analyze, make decision, and perform action). Delivery of weekly locomotion scores was also described in other automatic locomotion scoring systems (Bicalho et al., 2007; de Mol et al., 2013).

Beside observers, other important factors affecting the probability for classifying a cow as lame were presence of hoof lesions and the parity number. The presence of horn lesions and a combination of skin/ horn lesions increased the probability for classifying cows as lame. Because presence of skin lesions (only) did not have a significant effect on the probability of classifying cows as lame, the significant effect of presence of skin/horn lesions is probably due to the presence of horn lesions and not due to skin lesions. Association between horn lesions and lameness has been previously reported by other studies (Tadich et al., 2010; Thomsen et al., 2012). The fact that horn lesions are more associated with lameness than skin lesions and hyperplasia is probably due to differences in pain perception (defined as retraction of a limb when pressure is exerted on hooves). To our knowledge, no study reports a direct association between presence of specific hoof lesions and pain. However, several studies report that cows classified as lame required less pressure to produce limb retraction (i.e., painful hoof) than cows classified as nonlame (Whay et al., 1997; Dyer et al., 2007; Dunthorn et al., 2015). Thus, because horn lesions are more associated with lameness than skin lesions and interdigital hyperplasias, it is possible to infer that horn lesions are more painful than skin lesions and hyperplasias. Cows in 2 nd and $\geq 3$ rd parity had a higher probability of being classified as lame than cows in 1st parity, which could be partially explained by the higher probability of horn lesions in older cows (Solano et al., 2016). However, cows with a parity number $\geq 1$ are more likely to be classifying as lame even without the presence of hoof lesions (Flower and Weary, 2006).

Although cows classified as lame were more likely to have horn lesions, human observers showed only moderate performance for detecting horn lesions and combinations of skin/horn lesions and poor performance for detecting skin lesions and a combination of skin/ hyperplasias. Other studies reported similar moderate performance from observers detecting sole ulcers $\left(\mathrm{PA}_{\text {lesion } / \text { nonlesion }}=66 \%, \mathrm{SEN}_{\text {lesion }}=54 \%, \mathrm{SPE}_{\text {nonlesion }}=\right.$ $70 \%$, Chapinal et al., 2009b) and painful lesions, defined as retreatment of the limb when digital pressure was applied to the lesion $\left(\mathrm{SEN}_{\text {lesion }}=67 \%, \mathrm{SPE}_{\text {nonlesion }}\right.$ $=84 \%$, Bicalho et al., 2007). Moderate to poor per- 
formance for detecting hoof lesions can be explained by a combination of different factors. First, cows that were affected by a hoof lesion could not be classified as lame by observers. This is probably the case of cows classified as slightly impaired locomotion (locomotion score $=3$ ), which are most difficult for observers to detect (Schlageter-Tello et al. 2014a). Second, poor performance in detecting hoof lesions by locomotion scores could be related to lesions that do not produce impaired locomotion (i.e., nonpainful lesions). This is generally the case of most skin lesions (i.e., digital and inter-digital dermatitis) that produce impaired locomotion only in a few severe cases, whereas the majority of slight skin lesions do not produce impaired locomotion (Frankena et al., 2009). A final factor for poor to moderate lesion detection lies in cows that despite being affected by lesions that could be considered painful do not show impaired locomotion. Dyer et al. (2007) reported that approximately $37 \%$ of hooves that were classified as painful (retraction of the limb when pressure was exerted on the hoof) did not show impaired locomotion.

The 3D-ALS had poor overall performance for detecting cows affected by skin and horn lesions and combinations of skin/horn lesions and skin/hyperplasias as reflected in poor values for $\mathrm{PA}_{\text {lesion/nonlesion }}$ and $\kappa_{\text {lesion/nonlesion. }}$. However, $\mathrm{SEN}_{\text {lesion }}$ values obtained by 3D-ALS for detecting horn lesions were similar to $\mathrm{SEN}_{\text {lesion }}$ values obtained by human observers. Similar and acceptable values for $\mathrm{SEN}_{\text {lesion }}$ for horn lesions for observers and 3D-ALS are probably associated with an overestimation of lameness by 3D-ALS when compared with observers. By overestimating lameness cases, the 3D-ALS increase the probability for detecting horn ulcers reaching a similar performance to humans at the cost of having a higher number of false positives when compared with observers (as suggested by low $\mathrm{SPE}_{\text {nonlesion }}$ and low $\kappa_{\text {lesion/nonlesion }}$ values).

To our knowledge only one manuscript has reported on the performance for detecting hoof lesions of an automatic locomotion scoring systems based on the measurement of forces exerted on the floor by hooves using force-plates. The automatic force-plates system showed lower $\mathrm{SEN}_{\text {lesion }}(33.3 \%)$ and higher $\mathrm{SPE}_{\text {nonlesion }}$ $(89.9 \%)$ than the 3D-ALS described in the current article (Bicalho et al., 2007). Differences in the performance of both 3D-ALS and the force-plates automatic system for detecting hoof lesions could be explained by the utilization of different sensors (force-plates vs. 3D cameras); locomotion parameter assessed (gait vs. back curvature); differences in the algorithms used for the assignment of a locomotion score to cows; and type of lesion to be detected, painful lesions (defined as retreat- ment of the limb when digital pressure was applied to the lesion) vs. specific lesions.

For the 4 models estimating the probability for being affected by type(s) of lesions, there was no significant effect for the interaction of observer and lame classification indicating that there was no difference between observers and 3D-ALS in detecting types of lesions when a cow was classified as lame. Cows with parity number $\geq 2$ had higher probabilities for being affected by skin and horn lesions than cows with parity $=1$, which is in agreement with previous research (Barker et al., 2009; Solano et al., 2016). Finally, cows had lower probability of being affected by different type(s) of hoof lesions in session 2 when compared with session 1 . With regard to this, the farmer performed several routine tasks to improve hoof health, and the hoof trimming performed on all cows in session 1 may have helped in reducing the prevalence of hoof lesions in session 2 due to the preventive and healing effect of hoof trimming (Manske et al., 2002; Groenevelt et al., 2014). Another possible explanation for the reduction in lesion prevalence in session 2 is related to the Hawthorne effect, defined as a change of behavior of individuals due to the awareness of being part of research (McCambridge et al., 2014). Awareness of being part of research in combination with awareness of a high hoof lesion prevalence in session 1 could lead farmers to change their behavior toward hoof health issues between both experimental sessions (e.g., increase or change of chemical solution in hoof baths, better follow-up of hoof lesions found in preventive trimming, or a better commitment to a routine hoof trimming plan).

Because lack of time is the main factor that farmers argue for having poor control of hoof lesions (Leach et al., 2010), the utilization of the described 3D-ALS could be an important contribution to hoof health plans in modern dairy farms. The described 3D-ALS was able to perform automatic and continuous monitoring of cows within the farm with a similar performance to observers for detecting lame cows and horn lesions (as indicated by $\mathrm{SEN}_{\text {lame }}$ and $\mathrm{SEN}_{\text {lesion }}$ for observers and 3D-ALS). Despite its potential, the 3D-ALS showed several issues associated with practical application. For instance, 3D-ALS delivered an important number of false positives (when compared with human observers) that could be time consuming when cows classified as lame but nonaffected by hoof lesions are separated for treatment. In addition, a high number of false positives could also affect the trust of producers in the system. Cow crowding was a major problem for 3D-ALS in the current experimental setup, which could be resolved with a sorting gate before entering the setup. But this solution is challenging because important changes in 
farm design may be required (Van Hertem et al., 2017). In addition, further research is required to estimate the usefulness of 3D-ALS on different farms and under different practical conditions as well as the economic consequences of having an automatic locomotion scoring system instead of periodic locomotion scoring performed by humans.

\section{CONCLUSIONS}

Human observers and 3D-ALS showed similar sensitivity values for classifying lame cows as lame. However, specificity values for classifying nonlame cows as nonlame were lower for 3D-ALS when compared with human observers. Accordingly, overall performance of 3D-ALS for classifying cows as lame and nonlame was lower than for observers. Similarly, observers and 3DALS had comparable sensitivity values for detecting different types of hoof lesions when a cow was classified as lame (moderate performance for detecting horn lesions and a combination of skin/horn lesions and poor performance for detecting skin lesions and a combination of skin/hyperplasias). However, specificity values for detecting cows without lesions when classified as nonlame was lower for 3D-ALS than for human observers. This was translated in a poor overall performance of 3D-ALS for detecting cows affected and nonaffected by hoof lesions when compared with human observers. Considering that human observers and the 3D-ALS showed similar performance for classifying cows as lame and for detecting horn lesions, the 3D-ALS could be a useful tool to improve hoof health in dairy farms.

\section{ACKNOWLEDGMENTS}

The authors thank the support and patience of the farmer and other farm personnel when performing the experiments. This study was part of the European Union Marie Curie Initial Training Network BioBusiness (FP7-PEOPLE-ITN-2008, Brussels) and funded by the Industrial Research Fund (IOFHB/13/0136, Brussels) of the Flemish government, which the authors thank for their financial support.

\section{REFERENCES}

Alberta Dairy Hoof Health Project. 2014. Dairy claw lesion identification. Alberta, Canada.

Alsaaod, M., C. Romer, J. Kleinmanns, K. Hendriksen, S. Rose-Meierhofer, L. Plumer, and W. Buscher. 2012. Electronic detection of lameness in dairy cows through measuring pedometric activity and lying behavior. Appl. Anim. Behav. Sci. 142:134-141.

Archer, S. C., M. J. Green, and J. N. Huxley. 2010. Association between milk yield and serial locomotion score assessments in UK dairy cows. J. Dairy Sci. 93:4045-4053.
Archer, S. C., M. J. Green, A. Madouasse, and J. N. Huxley. 2011. Association between somatic cell count and serial locomotion score assessments in UK dairy cows. J. Dairy Sci. 94:4383-4388.

Barkema, H. W., J. D. Westrik, K. A. S. Vankeulen, Y. H. Schukken, and A. Brand. 1994. The effects of lameness on reproductive-performance, milk-production and culling in Dutch dairy farms. Prev. Vet. Med. 20:249-259.

Barker, Z. E., J. R. Amory, J. L. Wright, S. A. Mason, R. W. Blowey, and L. E. Green. 2009. Risk factors for increased rates of sole ulcers, white line disease, and digital dermatitis in dairy cattle from twenty-seven farms in England and Wales. J. Dairy Sci. 92:1971-1978

Barker, Z. E., K. A. Leach, H. R. Whay, N. J. Bell, and D. C. J. Main. 2010. Assessment of lameness prevalence and associated risk factors in dairy herds in England and Wales. J. Dairy Sci. 93:932-941.

Bicalho, R. C., S. H. Cheong, G. Cramer, and C. L. Guard. 2007. Association between a visual and an automated locomotion score in lactating Holstein cows. J. Dairy Sci. 90:3294-3300.

Burn, C. C., and A. A. S. Weir. 2011. Using prevalence indices to aid interpretation and comparison of agreement ratings between two or more observers. Vet. J. 188:166-170.

Chapinal, N., A. M. de Passille, and J. Rushen. 2009a. Weight distribution and gait in dairy cattle are affected by milking and late pregnancy. J. Dairy Sci. 92:581-588.

Chapinal, N., A. M. de Passille, D. M. Weary, M. A. G. von Keyserlingk, and J. Rushen. 2009b. Using gait score, walking speed, and lying behavior to detect hoof lesions in dairy cows. J. Dairy Sci. 92:4365-4374.

Cicchetti, D. V., and A. R. Feinstein. 1990. High agreement but low kappa: II. Resolving the paradoxes. J. Clin. Epidemiol. 43:551-558.

Coggon, D., C. Martyn, K. T. Palmer, and B. Evanoff. 2005. Assessing case definitions in the absence of a diagnostic gold standard. Int. J. Epidemiol. 34:949-952.

Cook, N. B. 2003. Prevalence of lameness among dairy cattle in Wisconsin as a function of housing type and stall surface. J. Am. Vet. Med. Assoc. 223:1324-1328.

DairyCo. 2007. DairyCo mobility score. DairyCo, Kenilworth, Warwickshire, UK.

de Mol, R. M., G. André, E. J. B. Bleumer, J. T. N. van der Werf, Y. de Haas, and C. G. van Reenen. 2013. Applicability of day-to-day variation in behavior for the automated detection of lameness in dairy cows. J. Dairy Sci. 96:3703-3712.

Dippel, S., M. Dolezal, C. Brenninkmeyer, J. Brinkmann, S. March, U. Knierim, and C. Winckler. 2009. Risk factors for lameness in freestall-housed dairy cows across two breeds, farming systems, and countries. J. Dairy Sci. 92:5476-5486.

Dohoo, I., W. Martin, and H. Stryhn. 2003. Screening and diagnostic tests. Pages 85-120 in Veterinary Epidemiologic Research. AVC Inc., Charlottetown, Canada.

Dunthorn, J., R. M. Dyer, N. K. Neerchal, J. S. McHenry, P. G. Rajkondawar, G. Steingraber, and U. Tasch. 2015. Predictive models of lameness in dairy cows achieve high sensitivity and specificity with force measurements in three dimensions. J. Dairy Res. 82:391-399.

Dyer, R. M., N. K. Neerchal, U. Tasch, Y. Wu, P. Dyer, and P. G. Rajkondawar. 2007. Objective determination of claw pain and its relationship to limb locomotion score in dairy cattle. J. Dairy Sci. 90:4592-4602.

Engel, B., G. Bruin, G. Andre, and W. Buist. 2003. Assessment of observer performance in a subjective scoring system: Visual classification of the gait of cows. J. Agric. Sci. 140:317-333.

Espejo, L. A., M. I. Endres, and J. A. Salfer. 2006. Prevalence of lameness in high-producing Holstein cows housed in freestall barns in Minnesota. J. Dairy Sci. 89:3052-3058.

Flower, F. C., and D. M. Weary. 2006. Effect of hoof pathologies on subjective assessments of dairy cow gait. J. Dairy Sci. 89:139-146.

Flower, F. C., and D. M. Weary. 2009. Gait assessment in dairy cattle. Animal 3:87-95.

Frankena, K., J. Somers, W. G. P. Schouten, J. V. van Stek, J. H. M. Metz, E. N. Stassen, and E. A. M. Graat. 2009. The effect of 
digital lesions and floor type on locomotion score in Dutch dairy cows. Prev. Vet. Med. 88:150-157.

Groenevelt, M., D. C. J. Main, D. Tisdall, T. G. Knowles, and N. J. Bell. 2014. Measuring the response to therapeutic foot trimming in dairy cows with fortnightly lameness scoring. Vet. J. 201:283-288.

Hosmer, D. W., and S. Lemeshow. 2000. Applied Logistic Regression. John Wiley \& Sons, New York, NY.

Kottner, J., L. Audigé, S. Brorson, A. Donner, B. J. Gajewski, A. Hróbjartsson, C. Roberts, M. Shoukri, and D. L. Streiner. 2011. Guidelines for Reporting Reliability and Agreement Studies (GRRAS) were proposed. J. Clin. Epidemiol. 64:96-106.

Landis, J. R., and G. G. Koch. 1977. Measurement of observer agreement for categorical data. Biometrics 33:159-174.

Leach, K. A., H. R. Whay, C. M. Maggs, Z. E. Barker, E. S. Paul, A. K. Bell, and D. C. J. Main. 2010. Working towards a reduction in cattle lameness: 1 . Understanding barriers to lameness control on dairy farms. Res. Vet. Sci. 89:311-317.

Maertens, W., J. Vangeyte, J. Baert, A. Jantuan, K. C. Mertens, S. De Campeneere, A. Pluk, G. Opsomer, S. Van Weyenberg, and A. Van Nuffel. 2011. Development of a real time cow gait tracking and analysing tool to assess lameness using a pressure sensitive walkway: The GAITWISE system. Biosyst. Eng. 110:29-39.

Main, D. C. J., Z. E. Barker, K. A. Leach, N. J. Bell, H. R. Whay, and W. J. Browne. 2010. Sampling strategies for monitoring lameness in dairy cattle. J. Dairy Sci. 93:1970-1978.

Manske, T., J. Hultgren, and C. Bergsten. 2002. The effect of claw trimming on the hoof health of Swedish dairy cattle. Prev. Vet. Med. 54:113-129.

March, S., J. Brinkmann, and C. Winkler. 2007. Effect of training on the inter-observer reliability of lameness scoring in dairy cattle. Anim. Welf. 16:131-133.

McCambridge, J., J. Witton, and D. R. Elbourne. 2014. Systematic review of the Hawthorne effect: New concepts are needed to study research participation effects. J. Clin. Epidemiol. 67:267-277.

Rajkondawar, P. G., U. Tasch, A. M. Lefcourt, B. Erez, R. M. Dyer, and M. A. Varner. 2002. A system for identifying lameness in dairy cattle. Appl. Eng. Agric. 18:87-96.

Romanini, C. E. B., C. Bahr, S. Viazzi, T. Van Hertem, A. SchlageterTello, I. Halachmi, K. Lokhorst, and D. Berckmans. 2013. Application of image based filtering to improve the performance of an automated lameness detection system for dairy cows. ASABE, 21-24 July. Kansas City, Missouri.

Rutten, C. J., A. G. J. Velthuis, W. Steeneveld, and H. Hogeveen. 2013. Invited review: Sensors to support health management on dairy farms. J. Dairy Sci. 96:1928-1952.

Schlageter-Tello, A., E. A. M. Bokkers, P. W. G. Groot Koerkamp, T. Van Hertem, S. Viazzi, C. E. B. Romanini, I. Halachmi, C. Bahr, D. Berckmans, and K. Lokhorst. 2014a. Effect of merging levels of locomotion scores for dairy cows on intrarater and interrater reliability and agreement. J. Dairy Sci. 97:5533-5542.

Schlageter-Tello, A., E. A. M. Bokkers, P. W. G. Groot Koerkamp, T. Van Hertem, S. Viazzi, C. E. B. Romanini, I. Halachmi, C. Bahr, D. Berckmans, and K. Lokhorst. 2015a. Relation between observed locomotion traits and locomotion score in dairy cows. J. Dairy Sci. 98:8623-8633.

Schlageter-Tello, A., E. A. M. Bokkers, P. W. G. G. Koerkamp, T. Van Hertem, S. Viazzi, C. E. B. Romanini, I. Halachmi, C. Bahr, D. Berckmans, and K. Lokhorst. 2014b. Manual and automatic locomotion scoring systems in dairy cows: A review. Prev. Vet. Med. 116:12-25.

Schlageter-Tello, A., E. A. M. Bokkers, P. W. G. G. Koerkamp, T. Van Hertem, S. Viazzi, C. E. B. Romanini, I. Halachmi, C. Bahr, D. Berckmans, and K. Lokhorst. 2015b. Comparison of locomotion scoring for dairy cows by experienced and inexperienced raters using live or video observation methods. Anim. Welf. 24:69-79.

Solano, L., H. W. Barkema, S. Mason, E. A. Pajor, S. J. LeBlanc, and K. Orsel. 2016. Prevalence and distribution of foot lesions in dairy cattle in Alberta, Canada. J. Dairy Sci. 99:6828-6841.
Tadich, N., E. Flor, and L. Green. 2010. Associations between hoof lesions and locomotion score in 1098 unsound dairy cows. Vet. J. 184:60-65.

Thomsen, P. T. 2009. Rapid screening method for lameness in dairy cows. Vet. Rec. 164:689-690.

Thomsen, P. T., L. Munksgaard, and J. T. Sorensen. 2012. Locomotion scores and lying behaviour are indicators of hoof lesions in dairy cows. Vet. J. 193:644-647.

Thorup, V. M., L. Munksgaard, P. E. Robert, H. W. Erhard, P. T. Thomsen, and N. C. Friggens. 2015. Lameness detection via legmounted accelerometers on dairy cows on four commercial farms. Animal 9:1704-1712.

University of Bristol. 2004. Bristol welfare assurance program: Cattle assessment, Version 2.0. University of Bristol, Bristol, UK.

Van Hertem, T., C. Bahr, A. Schlageter Tello, S. Viazzi, M. Steensels, C. E. B. Romanini, C. Lokhorst, E. Maltz, I. Halachmi, and D. Berckmans. 2016. Lameness detection in dairy cattle: single predictor v. multivariate analysis of image-based posture processing and behaviour and performance sensing. Animal 10:1525-1532.

Van Hertem, T., A. Schlageter Tello, S. Viazzi, M. Steensels, C. Bahr, C. E. B. Romanini, K. Lokhorst, E. Maltz, I. Halachmi, and D. Berckmans. 2017. Implementation of an automatic 3D vision monitor for dairy cow locomotion in a commercial farm. Biosyst. Eng. https://doi.org/10.1016/j.biosystemseng.2017.08.011.

Van Hertem, T., S. Viazzi, M. Steensels, E. Maltz, A. Antler, V. Alchanatis, A. A. Schlageter-Tello, K. Lokhorst, E. C. B. Romanini, C. Bahr, D. Berckmans, and I. Halachmi. 2014. Automatic lameness detection based on consecutive 3D-video recordings. Biosyst. Eng. 119:108-116.

Van Nuffel, A., I. Zwertvaegher, S. Van Weyenberg, M. Pastell, V. M. Thorup, C. Bahr, B. Sonck, and W. Saeys. 2015. Lameness detection in dairy cows: Part 2. Use of sensors to automatically register changes in locomotion or behavior. Animals (Basel) 5:861-885

Vasseur, E., J. Gibbons, J. Rushen, and A. M. de Passille. 2013. Development and implementation of a training program to ensure high repeatability of body condition scoring of dairy cows. J. Dairy Sci. 96:4725-4737.

Viazzi, S., C. Bahr, A. Schlageter-Tello, T. Van Hertem, C. E. B. Romanini, A. Pluk, I. Halachmi, C. Lokhorst, and D. Berckmans. 2013. Analysis of individual classification of lameness using automatic measurement of back posture in dairy cattle. J. Dairy Sci. $96: 257-266$.

Viazzi, S., C. Bahr, T. Van Hertem, A. Schlageter-Tello, C. E. B. Romanini, I. Halachmi, C. Lokhorst, and D. Berckmans. 2014. Comparison of a three-dimensional and two-dimensional camera system for automated measurement of back posture in dairy cows. Comput. Electron. Agric. 100:139-147.

von Keyserlingk, M. A. G., A. Barrientos, K. Ito, E. Galo, and D. M. Weary. 2012. Benchmarking cow comfort on North American freestall dairies: Lameness, leg injuries, lying time, facility design, and management for high-producing Holstein dairy cows. J. Dairy Sci. 95:7399-7408.

Walker, S. L., R. F. Smith, J. E. Routly, D. N. Jones, M. J. Morris, and H. Dobson. 2008. Lameness, activity time-budgets, and estrus expression in dairy cattle. J. Dairy Sci. 91:4552-4559.

Warnick, L. D., D. Janssen, C. L. Guard, and Y. T. Grohn. 2001. The effect of lameness on milk production in dairy cows. J. Dairy Sci. 84:1988-1997.

Welfare Quality. 2009. Assessment Protocol for Cattle. In Welfare Quality Consortium. Lelystad, the Netherlands.

Whay, H. 2002. Locomotion scoring and lameness detection in dairy cattle. In Pract. 24:444-449.

Whay, H. R., A. E. Waterman, and A. J. F. Webster. 1997. Associations between locomotion, claw lesions and nociceptive threshold in dairy heifers during the peri-partum period. Vet. J. 154:155-161.

Winckler, C., and S. Willen. 2001. The reliability and repeatability of a lameness scoring system for use as an indicator of welfare in dairy cattle. Acta Agric. Scand. A Anim. Sci. 30:103-107. 